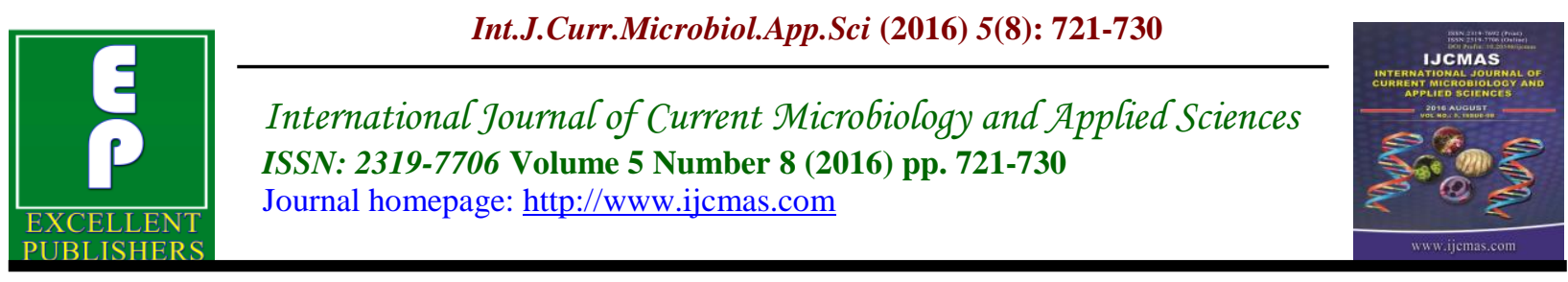

Original Research Article

http://dx.doi.org/10.20546/ijcmas.2016.508.081

\title{
A Bacteriological Study of Acute Pharyngitis in Children Aged 5-15 Years with Special Reference to Streptococcal Grouping
}

\author{
G. Naveen ${ }^{1 *}$, Harsha B Patil ${ }^{2}$ and Basavaraj V. Peerapur ${ }^{3}$ \\ ${ }^{1}$ Department of Microbiology, PESIMSR, Kuppam A.P India \\ ${ }^{2}$ Department of Pediatrics at Al-AMEEN Medical College, Bijapur, India \\ ${ }^{3}$ Department of Microbiology, RIMS, Raichur, Karnataka, India \\ *Corresponding author
}

\begin{abstract}
A B S T R A C T
Keywords

Acute

pharyngitis, $\beta$

hemolytic

streptococci,

children.

\begin{tabular}{l}
\hline Article Info \\
\hline Accepted: \\
28 July 2016 \\
Available Online: \\
10 August 2016
\end{tabular}

To know the bacteriological profile of acute pharyngitis in special reference to serological grouping of streptococci in children of 5-15 years age. Study included 100 cases of acute pharyngitis in children between the age group of 5-15 years who attended pediatric outpatient department. Throat swabs were collected from all the 100 cases and subjected to rapid group A streptococcus antigen detection, gram stain, culture and antibiotic sensitivity testing. Isolated $\beta$ hemolytic streptococcal colonies were grouped using pastorex strep latex kit. 80 cases were found bacterial culture positive among the 100 cases evaluated clinically. Among the 80 culture positive cases, 17 cases $(21.25 \%)$ were due to $\beta$ hemolytic streptococci. The grouping of $\beta$ hemolytic streptococci showed $13(76.47 \%)$ of them belonging to group A, $2(11.76 \%)$ to group C and $2(11.76 \%)$ to group $\mathrm{G}$. The present study showed a $21.5 \%$ prevalence of group A $\beta$ hemolytic streptococcus in the school going children of age 5-15 years suffering from acute pharyngitis. A significant amount of resistance $(17 \%)$ was seen among some of the commonly used antibiotics like ampicillin, azithromycin, erythromycin and cefuroxime.
\end{abstract}

\section{Introduction}

Acute pharyngitis is the most common upper respiratory tract infection responsible for significant morbidity in the childhood. Even though various bacteria and viruses are incriminated in the etiology, streptococci are of utmost importance worldwide. They are so common in school years that they are called "Occupational diseases of the school children (Kaplan et al., 1980). Apart from its high incidence, what makes the streptococci special is not the ability to cause adenitis, otitis media, otitis media, pneumonia or infrequently meningitis.
However, the mysterious pathogenic relationship to its non-suppurative sequelaee like acute rheumatic fever and acute poststreptococcal glomerulonephritis does make the organism unique. These non-suppurative sequelaee are still responsible for significant morbidity and mortality. Rheumatic heart disease remains the major cardiovascular disease in many parts of the world especially in non-developed countries. In India Rheumatic heart disease accounts for 16.5 to 50 percent of the cardiac patients attending OPD and wards in a hospital (OP Ghai $5^{\text {th }}$ 
edition). The clinical importance of understanding and preventing streptococcal infections and their sequelae is obvious.

Streptococcal infections of the upper respiratory tract could be of varying degree of severity. Various viral infections of the throat may mimic streptococcal pharyngitis in all respects. Experienced pediatricians are able to distinguish clinically between streptococcal and non-streptococcal pharyngitis with only 50-70\% accuracy (Wannamaker et al., 1972). Thus, throat culture has become the gold standard in substantiating the diagnosis of streptococcal pharyngitis.

Amongst the groups of streptococci causing human infections group A infections is not only prevalent, but also more severe and is responsible for post streptococcal sequelaee. The other groups produce rather milder diseases possibly there are several factors other than group of organism contributing to the severity of the disease. It has been categorically observed that development of acute glomerulonephritis is more common following skin infections rather than throat infections. Conversely, for rheumatic fever the predisposing infection is found in the throat. Further, the type incidence of streptococci could be responsible for the variations in the sequelaee. Streptococci produce mild upper respiratory infection in hot territories. The exact reason for which is not clearly known. Thus, patient may suffer repeated attacks with possible danger of developing sequelaee. Recently, there are reports of streptococci belonging to group $\mathrm{C}$ and $\mathrm{G}$ causing primary infection of upper respiratory tract and skin, occasionally group $\mathrm{C}$ infection leading to acute glomerulonephritis (Barnham et al., 1983). Recently, an entity known as Pediatric Autoimmune Neuropsychiatric Disorders Associated with Strep-Pyogenes (PANDAS) is described (Swedo et al., 1998). Hence, surveillance over streptococcal infections by means of microbiological and epidemiological surveys and follow-ups are very much needed in all parts of the world.

\section{Materials and Methods}

The study was a cross sectional study carried out at the Department of Microbiology, B.L.D.E.A's Shri B.M.Patil Medical College, Hospital and Research Center, Bijapur.

The study includes 100 cases of acute pharyngitis between the age group of 5-15 years who attended the Pediatric outpatient department of this hospital over a period of 16 months. The following patients were excluded from the study, if they met any one of the following criteria.

Patients who were presently taking antibiotics or had received antibiotics a week before presentation.

Cases of Diphtheria/Candidiasis.

Physical examination revealed evidence of lower respiratory tract infection.

Each case was then subjected to the following investigations:

\section{Blood}

1. $\mathrm{Hb} \%$, DC, TC, ESR, peripheral smear study.

2. C-reactive protein estimation.

3. Serum ASO titre estimation.

\section{Throat swab}

1. Gram stain

2. Antigen detection.

3. Culture and sensitivity.

4. Sero grouping.

Under good light and all aseptic precautions, 
the throat swab was collected after exerting light pressure over the tonsillar regions as well as posterior pharyngeal wall. Care was taken to avoid contamination with the oropharyngeal flora.

One of the collected swabs was used for rapid group $A$ streptococcal antigen detection. It is a latex agglutination test. In order to minimize the number of false negative tests, current US guidelines recommend using a throat swab culture to confirm a negative rapid test.

The other swab collected was used for gram stain followed by streaking the third swab collected on blood agar plates containing 5$7 \%$ defibrinated sheep blood and incubated under $5 \% \quad \mathrm{CO}_{2}$ aerobic condition for 24 hours.

After overnight incubation, the plates were red for $\beta$ hemolytic streptococcal colonies. Gram stained smears prepared from typical colonies were studied to confirm the organism.

Antibiotic sensitivity testing was carried out for the $\beta$ hemolytic colonies by disc diffusion method using penicillin, erythromycin, tetracycline, cephalexin, cefuroxime and azithromycin. The isolated $\beta$ hemolytic streptococcal colonies were subjected for grouping of group A, B, C, D, $\mathrm{F}$ and $\mathrm{G}$ using pastorex - strep latex kit. It is a rapid sensitive agglutination test. Streptococcal grouping of $\beta$ hemolytic colonies require extraction of these antigens from the colonies on blood agar plate. In the presence of antigen, the latex particles coated with homologous antibodies agglutinate very rapidly. $0.3 \mathrm{~mL}$ of extraction enzyme solution was taken in a test tube into which 5-6 colonies were added. The above was incubated for 10 minutes at $37^{\circ} \mathrm{c}$. The contents of the vials containing the latex particles were resuspended by shaking them vigorously for few seconds. One drop of each latex suspension was transferred to the corner of the agglutination card to which one drop of extract was added. The contents of each circle were homogenized by using plastic rods. The reaction was positive, if latex particles agglutinated within one minute. The positive reaction was indicated by white clumps on a black background, negative reaction by a uniform brown suspension.

ASO (antistreptolysin-O) test was done. 3 $\mathrm{mL}$ of blood was collection and the serum separated. A drop of serum was mixed with one drop of latex reagent on the slide using a disposable stirrer. The test slide was then gently rotated for 2 minutes to see further agglutination. The positive ASO result was indicated by the obvious agglutination pattern of the latex in a clear solution. The test has a detection limit of $200 \mathrm{IU} / \mathrm{mL}$ and above.

C-reactive protein estimation was done which is also a latex agglutination test that measures the protein and protein bound molecules. The test is expected to be positive with serum $\mathrm{C}$-reactive protein levels between 6 and $1000 \mathrm{mg} / \mathrm{L}$.

\section{Results and Discussion}

Among the 100 patients of acute pharyngitis, 57 were males and 43 were females. Most of the patients belonged to 58 years of age $(55 \%)$ followed by $9-11$ years $(27 \%)$ and $12-15$ years age $(18 \%)$.

$63 \%$ of the patients had an illness of $0-3$ day's duration, followed by 35\% with 4-6 days duration. Only 2 patients had a prolonged illness of more than 6 days. $71 \%$ of the patients had a history of overcrowding. 
Major symptoms were fever followed by cough and sore throat in percentage of $82 \%$, $72 \%$ and $60 \%$ respectively. Majority of the patients had fever ranging from 38.3 $39.4^{0} \mathrm{C}$. Congestion of anterior and posterior pillars of tonsils and posterior pharyngeal wall and tonsillar enlargement was seen in almost all cases. Tender lymph nodes were seen in $44 \%$. Chronic suppurative otitis media and pyoderma associated with acute pharyngitis were seen in significant number followed by vitamin A deficiency, Bcomplex deficiency and scabies.

Table.1 Organisms isolated on throat culture

\begin{tabular}{|l|l|c|c|}
\hline Sl. No. & \multicolumn{1}{|c|}{ Organism } & Number & Percentage \\
\hline 1. & Beta hemolytic streptococci & 17 & $21.25 \%$ \\
\hline 2. & Coagulase positive staphylococci & 14 & $17.5 \%$ \\
\hline 3. & Pneumococci & 24 & $30 \%$ \\
\hline 4. & Streptococcus viridians & 13 & $16.25 \%$ \\
\hline 5. & Brahmanella catarrhalis & 3 & $3.75 \%$ \\
\hline 6. & Coagulase negative staphylococci & 4 & $5 \%$ \\
\hline 7. & Mixed Total & 5 & $6.25 \%$ \\
\hline \multicolumn{1}{|c|}{ Total } & 80 & $100 \%$ \\
\hline
\end{tabular}

$\beta$ hemolytic streptococci were isolated in 17 (21.25\%) patients followed by coagulase Streptococcus viridans 13 (16.25\%). positive staphylococci 14 (17.5\%) and

Pneumococci were found in 24 cases (30\%).

Table.2 Analysis of symptoms

\begin{tabular}{|c|c|c|c|c|c|c|}
\hline \multirow{2}{*}{ Sl. No. } & \multirow{2}{*}{ Symptoms } & \multicolumn{2}{|c|}{ Non-streptococcal } & \multicolumn{2}{|c|}{ Streptococcal } & \multirow{2}{*}{$P$ value } \\
\hline & & No. & $\%$ & No. & $\%$ & \\
\hline 1. & Fever & 65 & 78.31 & 17 & 100 & $<0.05$ \\
\hline 2. & Sore throat & 45 & 54.21 & 15 & 88.23 & $<0.05$ \\
\hline 3. & Cough & 62 & 74.69 & 10 & 12 & $<0.05$ \\
\hline 4. & Headache & 5 & 6 & 13 & 15.66 & $<0.05$ \\
\hline 5. & Swelling in neck & 19 & 22.89 & 4 & 23.52 & $>0.05$ \\
\hline 6. & Abdominal pain & 4 & 4.81 & 5 & 29.41 & $<0.05$ \\
\hline 7. & Change in voice & 5 & 6 & 3 & 17.64 & $<0.05$ \\
\hline 8. & Feeding difficulty & 17 & 20.5 & 6 & 35.29 & $<0.05$ \\
\hline
\end{tabular}

All the symptoms were noted in higher percentage in streptococcal pharyngitis except cough, which was noted more commonly in non-streptococcal pharyngitis.

All the isolates of streptococci were sensitive to commonly used antibiotics like penicillin $(\mathrm{P})$, erythromycin $(\mathrm{E})$, tetracycline (Te), gentamycin (Gen), ampicillin (Amp), cefoperazone (Cpz), amoxyclav (Amc), azithromycin (Az), ciprofloxacin (Cip) and cefuroxime (Cf). The antibiotic sensitivity of the organisms is as follows. 
Table.3 Antibiotic sensitivity pattern of the isolates on throat culture

\begin{tabular}{|l|c|c|c|c|c|c|c|c|c|c|c|}
\hline Organisms & No. Isolated & P & E & Te & Gen & Amp & Cpz & Amc & Az & Cip & Cf \\
\hline BHS & 17 & 15 & 14 & 14 & 17 & 14 & 14 & 15 & 14 & 12 & 14 \\
\hline $\begin{array}{l}\text { Coagulase } \\
\text { Positive } \\
\text { staphylococci }\end{array}$ & 14 & 7 & 6 & 6 & 10 & 5 & 3 & 4 & 5 & 8 & 8 \\
\hline Pneumococci & 24 & 20 & 20 & 15 & 16 & 18 & 20 & 13 & 11 & 10 & 19 \\
\hline $\begin{array}{l}\text { Streptococci } \\
\text { viridians }\end{array}$ & 13 & 6 & 4 & 6 & 9 & 1 & 11 & 10 & 8 & 8 & 8 \\
\hline B. catarrhalis & 3 & - & - & 1 & 2 & 1 & - & 1 & - & 2 & 2 \\
\hline $\begin{array}{l}\text { Coagulase } \\
\text { negative } \\
\text { staphylococci }\end{array}$ & 4 & 1 & 1 & 1 & 1 & - & 1 & 2 & 2 & 1 & - \\
\hline Mixed & 5 & 2 & 2 & - & 4 & - & 3 & 2 & 4 & 2 & 3 \\
\hline
\end{tabular}

Table.4 Serological grouping of Streptococci found on culture N=17

\begin{tabular}{|c|c|c|c|}
\hline Sl. No. & Group & Number & Percentage \\
\hline 1. & A & 13 & $76.47 \%$ \\
\hline 2. & B & - & - \\
\hline 3. & C & 2 & $11.76 \%$ \\
\hline 4. & G & 2 & $11.76 \%$ \\
\hline
\end{tabular}

Out of 17 isolates of $\beta$ hemolytic streptococci $76.47 \%$ belong to group A and $11.76 \%$ belong to group $\mathrm{C}$ and group $\mathrm{G}$ each. CRP was positive in $55.5 \%$ of cases of streptococcal pharyngitis. In nonstreptococcal pharyngitis, the positivity rate was $33.33 \%$. ASO was positive in $59 \%$ cases of streptococcal pharyngitis. In nonstreptococcal pharyngitis, the positivity rate was $22.7 \%$. These cases may not have been properly picked-up by throat culture or it indicates a recent past streptococcal infection. In non-bacterial pharyngitis, the rate was $18.18 \%$ probably indicating recent past streptococcal infection.

Rapid antigen test for group A streptococci was positive in 9 cases among the 17 culture positive cases. Conversely in 3 cases where no growth was observed on culture, antigen for group A was positive. Thus, antigen detection test helps to identify streptococcal infection in culture negative cases and the test can be completed in few minutes. But, since the antigen test also did not detect the antigen in 8 out of 17 positive streptococcal cases, throat culture remains the gold standard for the isolation of streptococci.

Table.5 Streptococcal isolation rates in Indian workers

\begin{tabular}{|c|l|c|c|c|}
\hline Sl. No. & \multicolumn{1}{|c|}{ Author } & Year & Ref. No. & Isolation \% \\
\hline 1. & Vijay Gulati et al & 1981 & 55 & 33.3 \\
\hline 2. & Agarwal S.K. et al & 1981 & 48 & 15.50 \\
\hline 3. & Chakrabarti et al & 1989 & 56 & 80 \\
\hline 4. & Rajkumar et al al al & 1991 & 57 & 4 \\
\hline 5. & Soban Nandi t & 2002 & 47 & 13.39 \\
\hline 6. & Present study & 2010 & - & 21.25 \\
\hline
\end{tabular}


The streptococcal isolation among Indian workers ranged from a low of $4 \%$ to as high as $80 \%$ as shown in the above table. Our isolation of $21.25 \%$ was slightly higher than
$15.5 \%$ of Agarwal et al., Western workers have isolated streptococci ranging from $24 \%$ - $75 \%$ patients as shown in the following table.

Table.6 Streptococcal isolation percentage by different authors

\begin{tabular}{|c|l|c|c|c|}
\hline Sl. No. & \multicolumn{1}{|c|}{ Author } & Year & Ref. No. & Isolation \% \\
\hline 1. & Martin C. Randolf et al & 1985 & 58 & 75 \\
\hline 2. & Marvin S. Kober et al & 1985 & 50 & 59 \\
\hline 3. & Roddey et al & 1986 & 60 & 35.50 \\
\hline 4. & Mark C. Stein Hoff & 1997 & 52 & 24 \\
\hline
\end{tabular}

The following table 7 shows serological grouping of streptococci isolated from cases of streptococcal pharyngitis by different authors.

Table.7 Serological grouping of streptococci isolated from cases of Streptococcal pharyngitis by different authors

\begin{tabular}{|c|l|c|c|c|c|c|c|}
\hline \multirow{2}{*}{ Sl. No. } & \multirow{2}{*}{ Author } & \multirow{2}{*}{ Year } & \multirow{2}{*}{$\begin{array}{l}\text { Ref. } \\
\text { No. }\end{array}$} & & \multicolumn{4}{|c|}{ Sero group } \\
\cline { 5 - 8 } & & & & A & B & C & G \\
\hline 1. & Vijay Gulati et al & 1981 & 55 & 68 & 1 & 11 & 18 \\
\hline 2. & S.K. Agarwal et al & 1981 & 48 & 34.3 & 7.1 & 4.3 & 50 \\
\hline 3. & Brook et al & 1983 & 62 & 74 & 4 & 9 & 1 \\
\hline 4. & Julia et al & 1986 & 54 & 37.17 & 0.6 & - & 1.88 \\
\hline 5. & R. Gupta et al & 1992 & 64 & 73.5 & 2.12 & 0.7 & 23.5 \\
\hline 6. & Edmond K.M. et al & 1996 & 63 & 21.03 & - & 4 & 2 \\
\hline 7. & Present study & 2010 & - & 76.47 & - & 11.76 & 11.76 \\
\hline
\end{tabular}

All the studies isolated group A in highest percentage symptomatic patients except Grace Koshi (Grace Koshi et al., 1977) and S.K. Agarwal (Agarwal et al., 1981) who isolated group $\mathrm{G}$ in highest percentage.

In the present study group A streptococcus were isolated in number constituting $76.47 \%$ of streptococcal isolates followed by group $\mathrm{C}$ and group $\mathrm{G}$ in $11.76 \%$ each. No group $\mathrm{B}$ streptococci were isolated.
The following table shows the distributions of subgroups of streptococci among healthy children by different authors. All these studies isolated group $\mathrm{G}$ streptococci in highest numbers in asymptomatic carriers ranging from $43.2 \%$ to $60 \%$. In our study, we isolated group A and group $\mathrm{G}$ equally from the carriers in $42.8 \%$ followed by $14.2 \%$ of group C streptococci. 
Table. 8 Serogroups observed by different authors

\begin{tabular}{|c|l|c|c|c|c|c|c|c|c|c|}
\hline $\begin{array}{c}\text { Sl. } \\
\text { No. }\end{array}$ & Author & Year & $\begin{array}{c}\text { Ref. } \\
\text { No. }\end{array}$ & BH & \multicolumn{6}{|c|}{ Sero groups in \% } \\
\hline & & & & & A & B & C & G & F & NG \\
\hline 1. & Agarwal et al & 1981 & 48 & 7.9 & 12 & 2 & 8 & 60 & - & 8 \\
\hline 2. & Gulati et al & 1981 & 55 & 6 & 33.3 & - & 16.6 & 50 & - & - \\
\hline 3. & Srivastava et al & 1981 & 68 & 28.5 & 25.4 & 9.8 & 4.1 & 53.3 & - & 7.4 \\
\hline 4. & Pati et al & 1989 & 69 & 8.8 & 26.4 & 2.6 & 18.4 & 52.6 & - & - \\
\hline 5. & Navaneeth et al & 1998 & 66 & 21.6 & 28.8 & 1.9 & 11.5 & 43.2 & 0.9 & 13.4 \\
\hline 6. & Present study & 2010 & - & 14 & 42.8 & - & 14.2 & 42.8 & - & - \\
\hline
\end{tabular}

Table.9 Comparison of ASO positivity in Streptococcal pharyngitis

\begin{tabular}{|c|l|c|}
\hline SI. No. & \multicolumn{1}{|c|}{ Author } & Percentage \\
\hline 1. & Grace Koshi et al & 48.4 \\
\hline 2. & Vijay Gulati et al & 45.3 \\
\hline 3. & Present study & 58.8 \\
\hline
\end{tabular}

In our study, we found 59\% of ASO positivity in streptococcal pharyngitis, which was slightly high, compared to studies by Grace Koshi (Grace Koshi et al., 1977) $8.4 \%$ and Vijay Gulati (Vijay Gulati et al., 1981) $45.3 \%$.

Table.10 Comparision of C-reactive protein in Streptococcal pharyngitis

\begin{tabular}{|c|l|c|}
\hline Sl. No. & \multicolumn{1}{|c|}{ Author } & Percentage \\
\hline 1. & P. Padmini et al & 59.4 \\
\hline 2. & Edward L. Kaplan & 78 \\
\hline 3. & Present study & 55.55 \\
\hline
\end{tabular}

In our study, the positive percentage of Creactive protein in streptococcal pharyngitis was 55.55\%. P Padmini (Padmini et al., 1987) found $59.4 \%$ of positivity and Edward L. Kaplan (Edwar Kaplan et al., 1977) found the percentage to be as high as $78 \%$.

Acute pharyngitis is among the most common conditions responsible for significant morbidity in childhood. Even though majority of the cases are caused by viruses, it is important to know the bacteriologic etiologies with the treatment and complications point of view. $\beta$ hemolytic streptococci are not only common pathogens, but they are also important because of the severity of pharyngitis and the complications. Rheumatic heart disease as the common sequelae of streptococcal pharyngitis remains the major cardiovascular disease in many parts of the world especially in non-developed countries. In India, it is responsible for $33-50 \%$ of inpatient and outpatient attendance in cardiac clinics. Thus, streptococcal infections represent an important health and economic problem in our country. The importance of understanding the clinical profile and their sequelae is obvious. Various workers have carried out studies on streptococcal pharyngitis. 
Robert T. Rowe (Robert Rowe et al., 1977) and Robert T. Stone (Robert Rowe et al., 1977) reported the incidence of streptococcal pharyngitis as $33 \%$ in $2-5$ years age group, $45 \%$ in 6-10 years and $13 \%$ in 11-16 years of age (Robert Rowe et al., 1977). Sobhan Nandi (Sobhan Nandi et al., 2002) found out that $15 \%$ group A streptococcus positivity was seen in 9-12 years of age.

In the present study, we found higher incidence of $64.7 \%$ in 5-8 years age group followed by $17.6 \%$, in both $9-11$ and $12-15$ years age group. Thus, the peak age is 5-8 years.

Study conducted by Agarwal et al., found streptococcal pharyngitis of $16.1 \%$ in males and $14.4 \%$ in females. This was not significantly different. J.F. Bach (Bach et al., 1996) showed a slight female preponderance $11.2 \%$ as compared to $9.1 \%$ in males. Similar to it, N.B. Mathur also showed a female preponderance of $38.9 \%$ as to $15 \%$ in males. Sobhan Nandi (Sobhan Nandi et al., 2002) found $14.7 \%$ positivity in males compared to $11.7 \%$ among females. The present study shows slight preponderance of males $-58.8 \%$ to females $41.2 \%$ among the streptococcal isolates.

Michael A. Gerber (Michael Gerber et al., 1997) performed a study on streptococcal pharyngitis in Connecut and noted fever in $65 \%$, sore throat in $89 \%$, abdominal pain in $28 \%$, cervical adenitis $36 \%$, tonsillar exudates $22 \%$, enlarged tonsils in $33 \%$ and pharyngeal congestion in $79 \%$ of patients. James M. T. (James et al., 1993) in his study of streptococcal pharyngitis found $91 \%$ positivity for enlarged tonsils, $72 \%$ for fever, $60 \%$ tonsillar exudates and headache in $51 \%$ cases. Mark C. Stein Hoff (Stein Hoff et al., 1997) noted fever in $87.2 \%$ and tonsillar exudates in $22 \%$ pharyngitis cases.
In a study by Sobhan Nandi (Sobhan Nandi et al., 2002) most common symptoms of group A streptococcus sore throat was pain in the throat $(86.2 \%)$ and major signs were erythema of pharynx $(92.7 \%)$ enlarged tonsils $(86.9 \%)$ and lymphadenopathy $(87 \%)$.

Among the signs, congestion of anterior pillar, posterior pillar and posterior pharyngeal wall and tonsillar enlargement are almost same in both streptococcal and non-streptococcal pharyngitis.

Streptococcal isolation rates from symptomatic patients vary widely among various workers.

In conclusion, the present study showed a $21.5 \%$ prevalence of group A $\beta$ hemolytic streptococcus in the school going children of age 5-15 years suffering from acute pharyngitis. A significant amount of resistance $(17 \%)$ was seen among some of the commonly used antibiotics like ampicillin, azithromycin, erythromycin and cefuroxime.

This study emphasis the importance for screening of pathogens like streptococcus pyogenes and other $\beta$ hemolytic streptococci in acute tonsillitis in children to avoid further complications and better outcome of the patient. Prompt screening and performing routine culture and sensitivity testing can help in avoiding the drug resistance to the commonly used antibiotics which may develop due to excessive and injudicious use of antibiotics without proper antibiotic policy.

\section{References}

Agarwal, S.K., Srivastava, V.K., Mallik, G.K. 1981. Streptococcal throat infection in urban school children. Ind. Pediatr., 18: 797-800. 
Barnham, M., Thornton, T.J., Lange, K. 1983. Nephritis caused by Streptococcus Zooepidemicus (Lan Gp C). Lancet, 1(8331): 945 -8.

Brook, I. 1983. Distribution of Beta hemolytic Streptococci in pharyngitis specimens obtained from children. Microbios., 36(145-146): 169-72.

Chakrabarthi, A.K., Ghosh, S., Halder, K.K. et al. 1997. Epidemiology of Group A streptococcal infection amongst children in different ethnic groups in Darjeelling. Indian J. Public Health, 41: 6-10, 32.

Edmond, K.M., Grimwood, K., Carlin, J.B. et al. 1996. Streptococcal pharyngitis in a paediatric emergency department. Med. J. Aust., 165(8): 420-3.

Edward, L., Kaplan, and Lewis, N., Wannamaker. 1977. C-reactive protein in streptococcal pharyngitis. Pediatr., 60(1): 28-32.

Grace Koshi and V. Benjamin. 1977. Surveillance of Streptococcal infections in children in a SouthIndian Community - A pilot study. Indian J. Med. Res., 66(3): 379-388.

Bach, J.F., S. Chalons, E. Forier et al. 1996. 10-year educational programme aimed at Rheumatic fever in two French Caribbean Islands. The lancet, 347: 644-648.

James, C., Turner, Alvin Fox, Karen Fox, et al. 1993. Role of Group C Beta hemolytic Streptococci in pharyngitis: Epidemiological study of clinical features associated with isolation of Group C Streptococci. J. Clin. Microbiol., 31(4): 808-811.

Julia, A., Mc Milan, Cathy Sandstrom, Leonard, B., Weiner, et al. 1986. Viral and Bacterial organisms associated with aucte pharyngitis in a school aged population. J. Pediatrics, 109(5): 747752.

Kaplan, E.L. 1980. The Group A
Streptococcal upper respiratory tract carrier state; an engema. The $J$. Pediatrics, 97(3): 337-45.

Martin, F., Randolph, Michael, A., Gerber, Kathleen, K. et al. 1985. Effect of antibiotic therapy on the clinical course of Streptococcal pharyngitis. The J. Pediatrics, 106 (6): 870-874.

Mathur, N.B. 1992. Bacteriological examination of pharyngeal secretions. Ind. Pediatr, 29: 1071-1075.

Michael, A., Gerber, Robert, R., Tanz, William, Kabat. et al. 1997. Optical Immunoassay test for Group A Beta hemolytic Streptococcal pharyngitis. JAMA, 277(11): 899 - 903.

Navaneeth, B., Nimananda, R., Chawda, S., et al. 2001. Prevalence of Beta hemolytic Streptococci carrier rate among school children in Salem. Indian J. Pediatr., 68: 985-986.

OP Ghai's Textbook of pediatrics $5^{\text {th }}$ edition; pp 274-278.

Padmini, P., Lata Kumar, N.K., Ganguly. 1987. Rapid diagnosis of streptococcal sore throat. Indian Pediatrics, 24: 744-45.

Pati, S.B., Jajodia, N.K., Chawda, S. et al. 1991. Beta hemolytic Streptococcal carrier among school children in western Orissa. Indian J. Pathol. Microbial., 34(4): 265-269.

Gupta, R., K. Prakash, A.K. Kapur. 1992. Sub-clinical Group A Streptococcal Throat infections in school children. Indian Pediatrics, 29: 1491 - 1494.

Rajkumar, S., Krishnamurthy, R. 2001. Isolation of Group A Beta hemolytic Streptococci in the tonsil of Pharynx of school children in Madras city and co-relation with their clinical features. Jpn. J. Infec. Dis., 54: 137-139.

Robert, T., Rowe, and Robert. T., Stone. 1997. Difficulties in diagnosis on clinical grounds alone "Streptococcal pharyngitis in children", Clin. 
Pediatrics, 16 (10): 933-935.

Roddey, O.F. et al. 1986. Comparision of latex agglutination test for four culture methods for identification of Group A Streptococci in a Pediatric office laboratory. J. Pediatrics, 108 (3): 347-351.

Soban Nandi, Rajesh Kumar, Pallab Ray et al. 2002. Clinical score card for diagnosis of Group A Streptococcal sore throat. Indian J. Pediatrics, 69: 471-475.

Srivastava, V.K., Agarwal, S.K., Chandra, M.R. et al. 1981. Beta hemolytic streptococcal throat carriage in a rural population of Lucknow. Ind. J. Med. Res., 73: 853-855.

Steinhoff, M.C., Abd el Khalek, M.K., Khallaf, N. et al. 1997. Effectivenss of clinical guidelines for presumptive treatment of streptococcal pharyngitis in children. Lancet, 350(9082): 91821.

Swedo, S.E., Leonard, H.L., Garvey, M. et al. 1998. Pediatric autoimmune neuropsychiatric disorders associated with Streptococcal infections: Clinical description of first 50 cases. American J. Psychiatry, 155 (2): 264-71.

Vijay Gulati, Harminder Prabhakar. 1981. A study of Beta hemolytic streptococci and antistreptolysin $\mathrm{O}$ Titer in acute pharyngitis in children. Ind. Ped., 18: 793-96.

Wannamaker, L.W. 1972. Perplexity and precision in the diagnosis of Streptococcal pharyngitis. Am. J. Dis. Child, 124: 352-58.

\section{How to cite this article:}

Naveen, G., Harsha B Patil and Basavaraj V. Peerapur. 2016. A Bacteriological Study of Acute Pharyngitis in Children Aged 5-15 Years with Special Reference to Streptococcal Grouping. Int.J.Curr.Microbiol.App.Sci. 5(8): 721-730. doi: http://dx.doi.org/10.20546/ijcmas.2016.508.081 